\title{
Đồng minh trong những việc khó khăn
}

\author{
Hồ Mạnh Toàn
}

AISDL

Ngày 20 tháng 12 năm 2020

Đồng minh đó là thời gian.

Khi nói đến "kiên nhẫn" thì có lẽ yếu tố đầu tiên gợi đến chính là thời gian. Rồi sau đó là những yếu tố: thực hành bền bỉ (cũng thời gian), chịu đựng khó khăn (qua thời gian), tìm tòi (kể cả việc hỏng rồi tìm tiếp, cũng là thời gian).

Nói cho chuẩn xác, thời gian là yếu tố rất quan trọng.

Thực ra, chẳng ai phủ nhận được điều này, vì về lý, cả sự sống chẳng qua cũng đo bằng thời gian.

Đối với công việc dữ liệu và nghiên cứu của AISDL, điều này có thể cảm nhận được khi đo các mốc thời gian đối với những mục tiêu đặt ra.

Trước tiên tạm xem như là lời hứa về "Open data, open review, open dialogue". Những mục tiêu này đưa ra năm 2017, trong bài [1], tại địa chỉ: https://go.nature.com/37y6nn0; coi chúng như khai sinh AISDL. Thực hiện chúng thật chẳng dễ dàng gì, khi mà xung đột về quan niệm "chi phí đầu tư khoa học" vẫn chưa thể nào dứt. Cuộc cãi vã "đắt-rẻ" mãi không đến hồi kết [2] (xem trên Nature Human Behaviour tại: https://www.nature.com/articles/s41562-017-0281-4).

Đến cuối 2018, một phần công việc mới hoàn thành, với việc xử lý kỹ thuật thống kê Bayesian đi tới sản phẩm vượt qua bình duyệt, trở thành ấn phẩm hoàn chỉnh [3] (xem:

https://www.nature.com/articles/s41599-018-0189-2). Đồng thời, CSDL tiết kiệm (tuân thủ [2]) và mở (tuân thủ [1]) mới được chấp thuận xuất bản trên Scientific Data của Nature [4] (xem: https://www.nature.com/articles/sdata2018188).

Tuy vậy, lại phải mất thêm thời gian nhiều tháng nữa để dần hoàn thiện các vấn đề kỹ thuật, và đưa ra quyết định quan trọng: xây dựng bayesvl trên R. Cuối cùng, tới tháng 5-2019, chương trình ứng dụng Bayesian trên $\mathrm{R}$ cũng vượt qua "peer review" và được chấp thuận xuất bản chính thức trên CRAN https://cran.r-project.org/package=bayesvl [5].

Những công việc khó nhọc này đã dẫn tới những suy nghĩ sâu hơn về công việc nghiên cứu trong thể trạng nền kinh tế đang phát triển. Nó đòi hỏi sự thay đổi quan điểm về năng suất khoa học, và cả cách đầu tư cho khoa học. Quan điểm này xuất bản tháng 10-2019, trong [6] trên Nature Human Behaviour tại: https://www.nature.com/articles/s41562-019-0667-6. Có thể xem nó như một phần mở rộng của [2].

Tuy vậy, bản thân chương trình bayesvl [5] cũng cần có thêm những ứng dụng mạnh và đủ chi tiết để chứng minh giá trị của nó. Một lần nữa, AISDL lại phải chọn việc khó mà làm. Đó là nghiên cứu kéo dài suốt 3 cái Tết, và chỉ tới tháng 5-2020 mới hoàn thành bình duyệt và xuất 
bản trên tạp chí Palgrave Communications của Nature Publishing Group, tại địa chỉ https://www.nature.com/articles/s41599-020-0442-3 [7].

Cuối cùng, để khép lại ví dụ ngốn rất nhiều thời gian này chính là mốc xuất bản bài trên Nature (mẹ) đầu tiên của AISDL: https://www.nature.com/articles/d41586-020-01694-x [8] vào ngày 8 tháng 6 năm 2020.

Thực sự những điểm cốt lõi đưa ra trong [1] đều rất "khó nhằn" đối với AISDL. Tuy nhiên, đó là chính là raison d'être của nhóm nghiên cứu, nên hoàn thành chúng cũng chính là xác nhận lẽ sống của toàn bộ chương trình nghiên cứu dài hạn. Vì thế nên chúng tôi làm gì còn lựa chọn nào khác.

Và cũng rất may mắn, kiên nhẫn, bền gan và liên tục lao động có được đồng minh rất quan trọng: Chúng tôi có đủ thời gian để hoàn thành những công việc, mà 8 hạng mục dưới đây chỉ điểm lại những gì được coi là tạo ra mốc thời gian hoàn thành đáng kể.

Bây giờ cũng là những ngày cuối tháng 12, sắp kết thúc năm 2020 đầy biến động khó khăn. Việc điểm lại công việc quá khứ có lẽ cũng là một cách chuẩn bị tinh thần để đón những mốc thời gian quan trọng tiếp theo trong năm 2021.

\section{References}

[1] Vuong, Q. H. (2017). Open data, open review and open dialogue in making social sciences plausible. Nature: Scientific Data Updates. (Dec. 12, 2017). Retrieved from: https://go.nature.com/37y6nn0

[2] Vuong, Q. H. (2018). The (ir)rational consideration of the cost of science in transition economies. Nature Human Behaviour, 2(1), 5.

[3] Vuong, Q. H., et al. (2018). Cultural additivity: behavioural insights from the interaction of Confucianism, Buddhism and Taoism in folktales. Palgrave Communications, 4(1), 143.

[4] Vuong, Q. H., et al. (2018). An open database of productivity in Vietnam's social sciences and humanities for public use. Scientific Data, 5, 180188.

[5] La, V. P., \& Vuong, Q. H. (2019). bayesvl: Visually learning the graphical structure of Bayesian networks and performing MCMC with 'Stan'. The Comprehensive R Archive Network (CRAN). https://cran.r-project.org/package=bayesvl

[6] Vuong, Q. H. (2019). Breaking barriers in publishing demands a proactive attitude. Nature Human Behaviour, 3(10), 1034.

[7] Vuong, Q. H., et al. (2020). On how religions could accidentally incite lies and violence: Folktales as a cultural transmitter. Palgrave Communications, 6(1), 82.

[8] Vuong, Q. H. (2020). Reform retractions to make them more transparent. Nature, 582(7811), 149. 